\title{
The Effect of Pre-Teaching New Vocabulary Items via Audio-Visuals on Iranian EFL Learners' Reading Comprehension Ability
}

\author{
Seyed Mohsen Mirhosseini Chahardeh ${ }^{1} \&$ Reza Khorasani ${ }^{2}$ \\ 1. Department of English Language, Ardabil Branch, Islamic Azad University, Ardabil, Iran \\ 2. Department of English Language, Ardabil Branch, Islamic Azad University, Ardabil, Iran \\ E-mail: seyedmohsenmirhosseini@hotmail.com
}

Received: September 10, 2017 Accepted: December 20, $2017 \quad$ Online Published: March 20, 2018

\begin{abstract}
This study aimed to investigate the effect of pre-teaching new vocabulary items via audio-visuals on Iranian EFL learners' reading comprehension ability. The question this study tried to answer is if pre-teaching new vocabulary items via audio-visuals have any effect on Iranian EFL learners' reading comprehension ability. To find the answer to the question, 30 intermediate level students from Rasht language institutes were selected via administrating OPT which divided them into two groups. They were both male and female. Intermediate level students were used for the current study because they were learning all skills of language at the same time, they were familiar with some words, and their English proficiency was enough to speak English and understand the importance of reading comprehension. The students were one experimental group (pre-teaching new vocabulary items via audio-visuals) and one control group (a placebo, teaching L2 reading comprehension via the existing method). The research was conducted during learners' classes within 5 sessions in summer course, 2016. The results indicated that pre-teaching new vocabulary items via audio-visuals affected positively the participant Iranian EFL learners' reading comprehension ability.
\end{abstract}

Keywords: vocabulary, pre-teaching new vocabulary, audio-visuals, reading comprehension ability, vocabulary schema

\section{Introduction}

Reading is really important to become successful not just in schools but throughout life. Through reading, we acquire new ideas and knowledge, acquire needed information, relax the minds, and improve our command of language and vocabulary. It also serves as a good companion, provides pleasure, expands our horizons, and enriches people's lives. Fortunately, libraries and bookshops can be easily found throughout the country and it's important to know how to make good use of them. But sadly, this is not the case as many of the young people only visit the libraries and bookstores during examinations or in times of need. Reading has come to hold the most significant place in education as a means of communication in a highly literate society. The book is still very much part of people's lives in the modern society and in spite of the invention of the latest audio-visual materials, the book in its ordinary conventional form is still the most important means of communication ever invented. Reading is important for acquiring knowledge and information. The enrichment in knowledge would, in turn, enable one to present oneself more confidently. From the very young to the old and the sick, there are books to suit every taste (Inderjit, 2014).

With the growing amount of digital information available and the increasing amount of time that people spend reading electronic media, the digital environment has begun to affect people's reading behavior. Smith and Mikulecky (1978), in their research with adult readers, found that reading contributes significantly to job success, career development, and ability to respond to change. The importance of reading has resulted in much research work conducted to understand the nature of the reading habits of individuals.

Anderson (1982), in learning English as a second or foreign language, asserts that reading is the most important skill to master. Due to Hedge (2003), any reading component of an English language course may include a set of learning goals for 
- the ability to read a wide range of texts in English. This is the long-range goal most teachers seek to develop through independent readers outside EFL/ESL classroom,

- building a knowledge of language which will facilitate reading ability,

- building schematic knowledge,

- the ability to adapt the reading style according to reading purpose (i.e. skimming, scanning),

- developing an awareness of the structure of written texts in English, and

- taking a critical stance to the contents of the texts.

The last goal can be implemented at an advanced level. Students, however, should be kept aware that not all Internet content is authentic since there are no "gate keepers" and anyone can post whatever he/she likes in this cyberspace. Consequently, students can check the authenticity of the text by looking at the following indicators: whether the article gives the name of the author or no, the date of publication, the aim of the article, etc.

\section{Review of the Literature}

According to Kelley and Serb (1961), "the use of audio-visual aids in the classroom will free the teacher from work" (p.81). Traditionally, some materials have been given more significance. That involves direct experience like visits and expeditions, real things like natural specimens and in museums. That also includes pictorial and graphic materials. Currently, projected materials and moving pictures are used. All these aids are hard to come by, and their use is temporal in everyday teaching. Visual perception contributes to about $90 \%$ to all human learning. By emphasizing on whatever is being said, visual aids help reach the targeted objectives. Clear pictures augment the audience's level of comprehension of the current material, and they should be used to reinforce your message, clarify points, and create excitement.

In many studies, experimental psychologists and scholars have found that retention of information three days after a meeting or other event is six times greater when information is presented by visual and oral means than when the information is presented by the spoken word alone. Studies by educational researchers suggest that approximately $83 \%$ of human learning occurs visually, and the remaining $17 \%$ through the other senses $-11 \%$ through hearing, $3.5 \%$ through smelling, $1 \%$ through tasting, and 1.5\% through touching. According to Rautrao (2012), 94\% of knowledge comes to us through the sense of sight and the sense of hearing. The studies suggest that three days after an event, people retain $10 \%$ of what they heard from an oral presentation, $35 \%$ from a visual presentation, and $65 \%$ from a visual and oral presentation.

The use of visual aids, then, is important in teaching. Without them, the impact of presentation may fade the audience shortly after the audience leaves. By preparing teaching English with visual aids that reinforce the main ideas, reaching the audience will be far more effective, and maybe will continue to "touch" them long after the presentation ends (Rautrao, 2012). By introducing or discussing words and their meanings prior to reading, students can begin to direct their thinking and focus on specific areas needed for comprehension. In-depth instruction in text-specific vocabulary will enhance prior knowledge and improve students' ability to form background necessary to make inferences, to make connections, and therefore, to understand difficult text (Blachowicz, Fisher, \& Ogle, 2006).

In many cases, students have no prior knowledge to associate with new information. Rosenblatt (1983) explained that teachers must integrate the students' framework and understanding along with the ideas offered by the text in order to understand the knowledge given in the text. Instruction in word meanings helped to overcome reading comprehension difficulty as well by giving students some information begin building background knowledge for a particular text or subject area. Background experiences are what readers use to develop, expand, and refine concepts that words represent (Rupley, Logan, \& Nichols, 1998-1999). Teaching word meanings helps to build the bridge between words that are known and those to be learned. Consequently, students encounter the new words in a positive manner rather than an unknown idea.

Pre-teaching is an instructional method that has been found to make a passage easier to comprehend by allowing the brain to focus on this comprehension and not decoding or determining the meaning of unknown words during target passage reading. This focus aided the student in the creation of a "vocabulary fluency" gaining the ability to be automatic and accurate in determining meaning while reading. The technique of pre-teaching helped to support the 
connection of vocabulary and comprehension instruction. Providing students with rich instruction focused on the content the students are reading, or are about to read, increased the likelihood that students' comprehension will improve (Graves, 2006). Having a strong understanding of the meanings of words ensured that students will be able to understand the text they are reading.

Beck, Perfetti, and McKeown (1982) explained that a vocabulary training program can lead to gain in comprehension. Following instruction, subjects process individual word meanings more accurately and more rapidly. Improvements in comprehension follow, because construction of passage meaning is made easier and individual word meanings are understood. Pre-teaching vocabulary provided the outlet of understanding unknown words prior to beginning to read a text and therefore, avoids this problem. Pre-teaching also incorporated instruction that provides both definitional and contextual information about the words to be learned as well as multiple exposures and opportunities to use them (Blachowicz, Fisher, \& Ogle, 2006).

When the classroom teacher introduced the vocabulary before reading, the student as a head starts on what terms and content will be addressed in the text. This activation of schema helped the reader to begin their interaction with the text. If there is no connection to these terms already, the pre-teaching would help to establish this background knowledge. If there is a connection to the terms, the pre-teaching would aid the reader activate the meanings of the terms. Beck et al. (1982) found that when main concepts are introduced prior to reading, both skilled and less skilled readers benefitted; in fact, less skilled readers performed just as well as the skilled readers from the control group receiving no prior knowledge activation.

Pre-teaching vocabulary has been found to be related to the access, instrumental, and knowledge effects of vocabulary knowledge as well as prior knowledge activation. Students that have been pre-taught vocabulary are able to comprehend a passage with more difficult words. Kameenui, Carnine, and Freschi (1982) conducted a study in which a control group was given a passage using easy words and the treatment group was given a passage with difficult synonyms substituted for those easy words. They found through the pre-teaching that the students that were pre-taught the difficult words had the same gains in comprehension as those who were given the easy words. "The substitution of familiar words for difficult or unfamiliar synonyms in a text makes the text easier to comprehend. People are helped to comprehend a text if they learn the meanings of the unfamiliar words it contains" (Kameenui, Carnine, \& Freschi, 1982, p.367).

Marks, Doctorow, and Witttrock (1974) had similar findings when they determined that there is better comprehension with high frequency words than with low frequency words. Changes from low to high word frequency facilitated reading comprehension. In their study, Brabham and Lynch-Brown (2002) found that students had increased word knowledge when the teacher explained the word meanings before and after a story that was read to them. Students had gains of $10 \%$ when assessed on word knowledge in instructed and uninstructed meanings during storybook reading (Biemiller \& Boote, 2006).

Pre-teaching vocabulary also had benefits in allowing students to improve reading comprehension and word knowledge over time. In their study, Beck et al. (1982) taught 104 words over a five-month period to elementary students. A variety of instructional methods were used and pretests and post-tests were given. After the study, there was a medium effect size demonstrating growth in reading comprehension. This study was replicated one year later to have a stronger focus on the improvement of reading comprehension. The results indicated that the vocabulary instruction prior to reading enhanced comprehension of the stories containing the instructed words. The study showed that students can thoroughly learn a year's worth of vocabulary over the course of 175 days through the use of reading comprehension integrated with word study. This study highlighted the importance of stressing breadth and depth of vocabulary learning in order to facilitate ownership.

Mihara (2011) focused on two pre-reading strategies: vocabulary pre-teaching and comprehension question presentation. He examined the effects of the two reading strategies and discussed the relationship between students' English proficiency and their reading comprehension. The participants in the present study were asked to perform a pre-reading strategy, read a passage, and then answer comprehension questions. They read four passages altogether. Three weeks after they read the fourth passage, they were asked to answer a questionnaire. This study indicates that vocabulary pre-teaching is less effective for Japanese students, although students with higher English proficiency outperformed lower-level students regardless of which pre-reading strategy they used. 


\section{Methodology}

\subsection{Design of the Study}

This study found a quantitative intact-group research design to be appropriate because it is statistically reliable and allows results to be analyzed and compared with similar studies. The current study consisted of two intact groups of intermediate EFL students. A pretest of reading comprehension was first administered to both groups, then the experimental group received pre-teaching new vocabulary items via audio-visuals while the other group (control group) did not receive any pre-teaching new vocabulary items via audio-visuals at all. Finally, there was a posttest to both groups to measure their reading comprehension ability.

\subsection{Participants}

The participants of this study consisted of 30 intermediate level students from Rasht language institutes. The students came from the same L1 background. The students' age range was from 16-20 years old. They were both male and female. Intermediate level students were ideal for the current study because they were learning all skills of language at the same time, their English proficiency was enough to speak English and to understand the importance of reading comprehension ability, but they were not high enough to understand reading comprehension quickly. The students were selected via administrating OPT which divided them into two groups, one experimental group (pre-teaching new vocabulary items via audio-visuals) and one control group (a placebo, teaching L2 reading comprehension via the existing method). The research was conducted during learners' classes within 5 sessions in summer course, 2016.

\subsection{Data Collection Materials}

This section elaborates on the instruments used in this research. These instruments used were: OPT, pretest of reading comprehension, and post-test of reading comprehension. In order to achieve maximum possible homogeneity among the subjects regarding their general English proficiency, an OPT test was administered at the beginning of the study. Then the selected students were divided into two groups, control group and experimental one. A pretest of reading comprehension was administered to the two groups of the study including experimental and the control groups. It was conducted in the form of multiple choices, with the reliability of 0.72 estimated by KR 21 formulas same rating scale used throughout the treatment itself, to gain information on their reading comprehension before the treatment and to compare it with the post-test taken at the end of the treatment. The test contained 20 general questions which examined the aspects in learners' reading comprehension.

\subsection{Procedure}

The students were divided into two groups, the experimental group received pre-teaching new vocabulary items via audio-visuals, and the control group received a placebo (teaching L2 reading comprehension via the traditional method). Prior to the treatment, a pretest was conducted to gain information on their reading comprehension proficiency and to compare it with the post-test taken at the end of the treatment. In pretest, the students were given a multiple choice test that all participants answered them. The questions consisted of a text with multiple choices that students must have answered. The total score for each participant was 20. The same process happened for the posttest.

After obtaining necessary information on the participants' reading comprehension through the pre-test, the treatment which lasted for about five sessions started. All of the students were given some reading comprehension in each session. Throughout the sessions, each participant in experimental group learned reading comprehension through preteaching new vocabulary items via audio-visuals. It meant that new vocabularies were shown to them by pictures and other visual tools.

At the end, a post-test was used, the same as the pretest, to evaluate the changes that had occurred in the participants' reading comprehension as the result of applying pre-teaching new vocabulary items via audio-visuals and a placebo (teaching L2 reading comprehension via the existing method). Then, the results of pre- and post-tests were compared with each other to see any possible changes that will be discussed in the following sections.

\subsection{Data Analysis}

The data obtained from testing the hypothesis of this study were analyzed via calculating the descriptive statistics as well as the inferential statistical method of an Independent Samples T-Test between the posttest scores of experimental and control group and one Paired Samples T-test, between the pretest and the posttest of the experimental group of 


\section{International Journal of Research in English Education}

the study for determining the effect of the independent variable of the study on the dependent variable, and the degree of progress of the participants from the pretest to the posttest of the study. The collected data were analyzed in order to answer the research questions.

\section{Results}

The analysis of the raw data related to the research question of the study was conducted in two phases using independent-sample t-tests and paired-samples t-test on the pretest scores and posttest scores. However, before one decides to run parametric tests, four assumptions should be met (Pallant, 2011).

- The data should be measured on an interval scale,

- The subjects should be independent, that is to say, their performance on the test is not affected by the performance of other students,

- The data should enjoy normal distribution, and

- The groups should have homogeneous variances.

The present data are measured on an interval scale and the subjects' performance independently on the tests. The assumption of normality is also met, since the Kolmogorov-Smirnov statistics for both groups is non-significant (Pallant, 2011).

Table 4.1 The results of Kolmogrov-Smirnov test of normality for the pre-test scores

\begin{tabular}{llllll}
\hline & & $\begin{array}{l}\text { Pretest of } \\
\text { Teaching } \\
\text { Vocabulary }\end{array}$ & $\begin{array}{l}\text { Pre- } \\
\text { Tosttest of Pre- Pretest of } \\
\text { Vocabulary }\end{array}$ & $\begin{array}{l}\text { Pre-Teaching } \\
\text { Vocabulary }\end{array}$ & $\begin{array}{l}\text { Posttest of Non } \\
\text { Pre-Teaching } \\
\text { Vocabulary }\end{array}$ \\
\hline $\mathrm{N}$ & & 15 & 15 & 15 & 15 \\
Normal Parameters ${ }^{\mathrm{a}, \mathrm{b}}$ & Mean & 14.8000 & 18.4667 & 14.8000 & 14.6667 \\
& Std. & .94112 & 1.24595 & 4.36218 & .89974 \\
& Deviation & & & & \\
Most Extreme Differences & Absolute & .202 & .266 & .342 & .237 \\
& Positive & .202 & .147 & .168 & .237 \\
& Negative & -.184 & -.266 & -.342 & -.178 \\
Kolmogorov-Smirnov Z & & .784 & 1.029 & 1.323 & .919 \\
Asymp. Sig. (2-tailed) & & .571 & .240 & .060 & .367 \\
& & & & & \\
\hline
\end{tabular}

As seen in Table 4.1, a Kolmogrov-Smirnov test of normality was conducted to compare the pretest scores for the control and the experimental groups. There was no significant difference in the scores for the control group and the experimental group. The magnitude of the differences in the Asymyp. Sig was very small (less than 1). Thus, it can be concluded that the two groups enjoyed the same level of reading comprehension prior to the main study.

To test the research hypothesis, stating that the use of pre-teaching new vocabulary via audio-visuals does not have any significant effect on improving Iranian EFL learners' reading comprehension ability, first, an independent samples t-test was implemented to compare the experimental and control groups' mean scores on the reading comprehension pretest and the effect size was calculated. The objective was to make sure that the two groups enjoyed the same level of reading comprehension ability prior to the main study. As displayed in Table 4.2, the mean scores for the control and experimental groups on the pretest are 10.0161 and 9.8065 , respectively. 


\section{International Journal of Research in English Education}

Table 4.2 Statistics of the groups on the pre-test

\begin{tabular}{ccccc}
\hline Group & Mean & N & Std. Deviation & Variance \\
\hline Experimental & 14.8000 & 15 & .94112 & 0.886 \\
Control & 14.8000 & 15 & 4.36218 & 19.029 \\
\hline
\end{tabular}

Table 4.3 Results of Independent-Samples T-test to compare the groups' scores on the pre-test

\begin{tabular}{|c|c|c|c|c|c|c|}
\hline $\mathrm{t}$ & $\mathrm{df}$ & Sig. (2-tailed) & $\begin{array}{l}\text { Mean } \\
\text { Difference }\end{array}$ & $\begin{array}{l}\text { Std. Error } \\
\text { Difference }\end{array}$ & $\begin{array}{l}95 \% \text { Confidence } \\
\text { Difference }\end{array}$ & Interval of the \\
\hline & & & & & Lower & Upper \\
\hline .000 & 28 & .1000 & .0000 & 1.15222 & -2.36022 & 2.36022 \\
\hline
\end{tabular}

Eta Squared: $=.000$

As seen in Tables 4.2 and 4.3, an independent-samples t-test was conducted to compare the pretest scores for the control and the experimental groups. There was no significant difference in the scores for the control group ( $\mathrm{M}=$ 14.8000, $\mathrm{SD}=4.36218)$ and the experimental group $(\mathrm{M}=14.8000, \mathrm{SD}=0.94112$; two-tailed $)$. The magnitude of the differences in the means was very small (eta squared $=.000$ ). Thus, it can be concluded that the two groups enjoyed the same level of reading comprehension prior to the main study.

In the second stage, an independent t-test was run to compare the experimental and control groups' mean scores on the posttest in order to probe the effect of pre-teaching new vocabulary via audio-visuals on improving the learners' reading comprehension ability. As displayed in Table 4.4, the mean scores for the control and experimental groups on the posttest are 12.96 and 14.22 , respectively.

Table 4.4 Statistics of the groups on the post-test

\begin{tabular}{lllll}
\hline Group & $\mathrm{N}$ & Mean & Std. Deviation & Variance \\
\hline Control & 15 & 14.6667 & .89974 & .810 \\
Experimental & 15 & 18.4667 & 1.24595 & 1.552 \\
\hline
\end{tabular}

Table 4.5 Results of Independent-Samples T-test to compare the groups' scores on the post-test

\begin{tabular}{|c|c|c|c|c|c|c|}
\hline \multirow[t]{2}{*}{$\mathrm{t}$} & \multirow[t]{2}{*}{$\mathrm{df}$} & \multirow[t]{2}{*}{ Sig. (2-tailed) } & \multirow[t]{2}{*}{$\begin{array}{l}\text { Mean } \\
\text { Difference }\end{array}$} & \multirow[t]{2}{*}{$\begin{array}{l}\text { Std. Error } \\
\text { Difference }\end{array}$} & \multicolumn{2}{|c|}{$\begin{array}{l}95 \% \text { Confidence Interval of the } \\
\text { Difference }\end{array}$} \\
\hline & & & & & Lower & Upper \\
\hline 9.576 & 28 & .000 & 3.80000 & .39681 & 2.98717 & 4.61283 \\
\hline
\end{tabular}

Eta Squared: $=.984$ 
As seen in Tables 4.4 and 4.5, an independent-samples t-test was conducted to compare the posttest scores for the control and the experimental groups. There was a significant difference in scores for the control group $(\mathrm{M}=14.6667$, $\mathrm{SD}=.89974)$ and the experimental group $(\mathrm{M}=18.4667, \mathrm{SD}=1.24595$; two-tailed $)$. The magnitude of the differences in the means (mean difference $=3.80000$ ) was high (eta squared $=.984$ ). Thus, it can be concluded that the null hypothesis is rejected:

H0: Pre-teaching new vocabulary items via audio-visuals does not have any effect on Iranian EFL learners' reading comprehension ability.

The experimental group outperformed the control group on the posttest. However, to calculate the magnitude of the effect of the treatment, a paired-sample t-test was conducted on the experimental group and the effect size was calculated.

Table 4.6 Results of Paired-Samples T-test on the experimental group's scores on the pre-test and the post-test

\begin{tabular}{|c|c|c|c|c|c|c|c|c|}
\hline & \multirow[t]{2}{*}{$\mathrm{t}$} & \multirow[t]{2}{*}{ df } & \multirow[t]{2}{*}{ Sig. (2-tailed) } & \multirow[t]{2}{*}{ M } & \multirow[t]{2}{*}{ SD } & \multirow[t]{2}{*}{ SEM } & \multicolumn{2}{|c|}{$\begin{array}{l}95 \% \text { Confidence Interval of } \\
\text { the Difference }\end{array}$} \\
\hline & & & & & & & Lower & Upper \\
\hline $\begin{array}{l}\text { Post-test } \\
\text { Pre-test }\end{array}$ & 29.103 & 14 & .000 & 3.366 & .48795 & .12599 & 3.39 & 3.93 \\
\hline
\end{tabular}

Eta Squared: $=.880$

As seen in Tables 4.2, 4.4, and 4.6, a paired-samples t-test was conducted to evaluate the impact of the intervention on students' scores on the reading comprehension test. There was a statistically significant increase in the scores from the pretest $(M=14.8000, S D=.94112)$ to the posttest $(M=18.4667, S D=1.24595), p<.0005$ (two-tailed). The mean increase in the scores was 3.6 with a $95 \%$ confidence interval. The eta squared statistic (.880) indicated a very large effect size. Here, it is concluded that that the use of pre-teaching new vocabulary via audio-visuals significantly improved the experimental groups' reading comprehension ability.

\section{Discussion and Conclusion}

The findings of the current study indicated that using pre-teaching new vocabulary items via audio-visuals in teaching English reading comprehension could result in a better performance of language learners in a test of English reading comprehension. These findings seem to be compatible with the findings of the research study made into the effectiveness of L2 reading comprehension teaching and learning through various activities or tasks. For example, Byrne (1987) claimed that learning to read and then improving and sustaining reading skills involves a variety of interconnected elements.

The findings of this study were also compatible to the findings of the study made by Carrel (1998), who stated that reading skill was essential since so much of what was needed to be known, especially in the academic context is communicated via the written mode. Effective reading is critical for long-term learning goals and it is especially important for students who care about their academic purposes. In Iran, most graduate students need to write a thesis in order to be graduated. Therefore, they need to spend a large amount of time reading expository texts and research articles including English texts and articles. However, reading is not easy to master and most students do not know how to read effectively and efficiently.

Accordingly, in order to compensate for the difficulties encountered by the EFL learners, teachers had to integrate reading comprehension teaching in their classroom syllabi so that the participants would become conscious of the ups and downs of reading comprehension of English as a foreign language. In this way, the Persian learners of English would be helped to become proficient readers of English with rare or no residue of misunderstandings of target words, phrases, or sentences, thereby leading to more intelligibility of their reading comprehension. 
Theoretically, the results of the current study can be considered a contribution in the latest theories and models of teaching L2 reading comprehension to the speakers of other languages. Such a contribution includes the enhancement of a sort of input named 'Pre-Teaching New Vocabulary via Audio-Visuals' in classroom which is supposed to result in a more dynamic way of teaching English reading comprehension. In addition, the present study has a prominent contribution in employing Pre-Teaching New vocabulary task as teaching tasks as well as their evaluating nature.

Pedagogically, the results of the study seem to be more practical and compatible to an Iranian situation of foreign language learning particularly for those who encounter problems regarding their English reading comprehension. First, the results of the current study are applicable to Iranian EFL learners who have made their minds to promote their L2 reading ability through strengthening their knowledge of English vocabulary. These learners can range from lowintermediate institute learners to freshmen university students at the B.A. level and senior M.A. candidates who feel a need for the knowledge.

Second, the results of this study may be beneficial to teachers of English as a foreign language (particularly Iranian teachers) in that they can devise innovative methods of teaching English reading comprehension by using pre-teaching new vocabulary as tasks or practices within classroom activities, and in this way, add to the degree of exposure of Iranian EFL learners to a more realistic situation of English language which can result in more exposure of the learners to English language reading comprehension patterns.

Third, material designers can take advantage of the results of the current study in that they may develop new curricula for teaching English reading comprehension at different levels or design materials to convey more information in teaching English reading comprehension. They can publish new books, pamphlets, or other teacher-made materials based on their specific classroom conditions. Finally, the results of this study can be usable for testers of English as a foreign language. Since reading comprehension ability can be considered a fundamental element and learners seem to be evaluated with their reading comprehension ability like other elements as the basic foundation of language, language testers can check their learners' knowledge of reading patterns to find out if they are competent enough in case of being exposed to pre-teaching new vocabulary task in L2 classes. Furthermore, testers can use the results of this study to devise newer measuring instruments of L2 learners' reading comprehension ability.

The present study suffered a major limitation during its conducting processes. That limitation corresponded to finding the corpus examples on pre-teaching new vocabulary via audio-visuals tasks. In spite of the fact that English language seems to be a language with a rather rich vocabulary corpus, finding numerous examples of them was difficult. A lot of time was spent to investigate the most appropriate task examples of pre-teaching vocabulary that were used in the study. To delimit the mentioned limitation of the study, the researcher made an attempt to follow the main two principles as follows:

- The researchers attempted to restrict the scope of the study to the pre-teaching vocabulary concepts at the level of "Audio-visuals" and more specifically to "English reading comprehension" since attributing the conception of "vocabulary" to other categories seemed unpractical or difficult to find.

- The researchers took advantage from different authentic resources to be able to present a reliable and valid collection of pre-teaching new vocabulary items examples.

Some ideas may be helpful for the improvement of the issue as future attempts in using pre-teaching new vocabulary items via audio-visuals in teaching English reading comprehension. The fact is that research in general and research in language reading comprehension are not limited fields. There are numerous topics to be worked on at least in terms of the variables discussed in this paper.

The first point to consider is the issue of population of the study. It seems possible to go beyond the sample-population limitations of the study and to elicit information from a larger population. This was not practical in this research since there was the problem of distance: it was not practical to have samples from all parts within the short period of the time allocated to writing this work; however, this is possible and the future researchers are advised to take the time and replicate the study from this point of view.

As the second point, the future researchers are advised to expand the replications of this study to other language teaching situations in Iran such as high schools. Despite all attempts made in this study to see the possible effect of using pre-teaching new vocabulary items via audio-visual task on the participants' achievement in English reading 


\section{International Journal of Research in English Education}

comprehension, the results seemed to be applicable to university levels as well. However, future researchers are advised to conduct qualitative research studies as well as quantitative ones to elicit information about the teachers/learners positive or negative views about the treatment and the results of the study.

\section{References}

Anderson, M. J. (1982). Reading attitudes of college students: Progress toward adequate assessment. Reading Improvement, 20(2),120-124.

Beck, I. L., Perfetti, C. A., \& McKeown, M. G. (1982). Effects of long-term vocabulary instruction on lexical access and reading comprehension. Journal of Educational Psychology, 74(4), 506-521.

Biemiller, A., \& Boote, C. (2006). An effective method for building meaning vocabulary in primary grades. Journal of Educational Psychology, 98(1), 44-6.

Blachowicz, C. L. Z., Fisher, P. J. L., Ogle, D., \& Watts-Taffe, S. (2006). Vocabulary: Questions from the classroom. Reading Research Quarterly, 41(4), 524-539.

Brabham, E. G., \& Lynch-Brown, C. (2002). Effects of teachers' reading-aloud styles on vocabulary acquisition and comprehension of students in the early elementary grades. Journal of Educational Psychology, 94(3), 465-473.

Byrne, D. (1987). Techniques for classroom interaction. London; New York: Longman.

Carrell, P. L. (1998). Can reading strategies be successfully taught? Australian Review of Applied Linguistics, 21(1), 1-20. doi: 10.1075/aral.21.1.01car

Graves, M. (2006). The vocabulary book: Learning and instruction. New York, NY: Teachers College Press.

Hedge, T. (2003). Teaching \& learning in the language classroom. UK: OUP.

Inderjit, S. (2014). Reading trends and improving reading skills among students in Malaysia. International Journal of Research in Social Sciences, 3(5), 70-81.

Kameenui, E. J., Carnine, D. W., \& Freschi, R. (1982). Effects of text construction and instructional procedures for teaching word meanings on comprehension and recall. Reading Research Quarterly, 17(3), 367-388.

Kelly, W., \& Serb, T. J. (1961). Audio-visual aids and equipment. Chicago: American Society of Planning Officials.

Marks, C. B., Doctorow, M. J., \& Wittrock, M. C. (1974). Word frequency and reading comprehension. The Journal of Educational Research, 67(4), 259-262.

Mihara, K. (2011). Effects of pre-reading strategies on EFL/ESL reading comprehension. TESL CANADA JOURNAL/REVUE TESL DU CANADA, 28(2), 51-73.

Pallant, J. (2011). SPSS survival manual: A step by step guide to data analysis using SPSS (4th edition). Australia: Allen \& Unwin.

Rautrao, S. (2012). Significance of audio-visual aids in teaching English. Indian Streams Research Journal, 2(9). doi: 10.9780/22307850 http://oldisrj.lbp.world/UploadedData/1480.pdf

Rosenblatt, L. M. (1983). The reading transaction: What for? In R. Parker \& F. Davis (Eds.), Developing literacy: Children's use of language. Newark, DE: International Reading Association.

Rupley, W. H., Logan, J. W., \& Nichols, W. D. (1998-1999). Vocabulary instruction in a balanced reading program. The Reading Teacher, 52(4), 336-346.

Smith, C. B., Smith, S. L., \& Mikulecky, L. (1978). Teaching reading in secondary school content subjects: A book thinking process. Holt, Rinehart and Winston. 